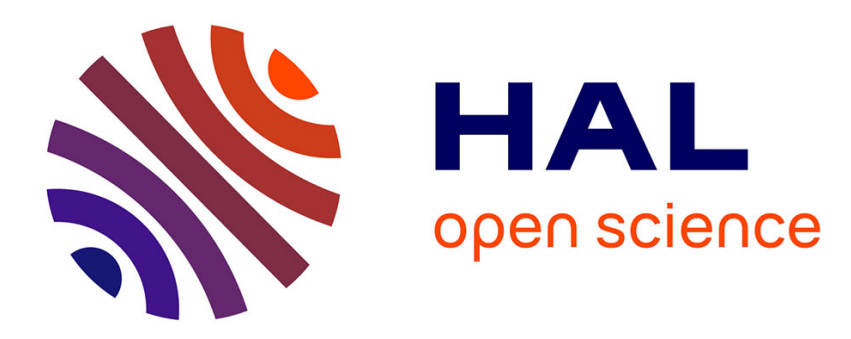

\title{
Thermal and dissipative effects accompanying Lüders band propagation
}

Hervé Louche, André Chrysochoos

\section{To cite this version:}

Hervé Louche, André Chrysochoos. Thermal and dissipative effects accompanying Lüders band propagation. Materials Science and Engineering: A, 2001, 307 (1-2), pp.15-22. 10.1016/S09215093(00)01975-4 . hal-03350121

\section{HAL Id: hal-03350121 \\ https://hal.science/hal-03350121}

Submitted on 21 Sep 2021

HAL is a multi-disciplinary open access archive for the deposit and dissemination of scientific research documents, whether they are published or not. The documents may come from teaching and research institutions in France or abroad, or from public or private research centers.
L'archive ouverte pluridisciplinaire HAL, est destinée au dépôt et à la diffusion de documents scientifiques de niveau recherche, publiés ou non, émanant des établissements d'enseignement et de recherche français ou étrangers, des laboratoires publics ou privés. 


\title{
Thermal and dissipative effects accompanying Lüders band propagation
}

\author{
Hervé Louche*, André Chrysochoos \\ LMGC UMR 5508 CNRS-Université Montpellier II, Pl. E. Bataillon, 34000 Montpellier, France
}

\begin{abstract}
This study deals with an experimental investigation of thermal and calorimetric effects induced by Lüders band propagation during monotonic and quasi-static tensile tests. One grade of steel is considered. Temperature variations were measured with an infrared camera on the surface of flat samples. Heat sources were deduced from thermal data using the local heat diffusion equation. For elastoplastic materials, when no phase transition occurs, the heat source is essentially due to intrinsic dissipation. The experiments revealed that a dissipation wave accompanied Lüders band propagation. Some characteristics of the wave, such as its shape, orientation and velocity, were derived from the experimental measurements and compared to previously published results. Finally, comparison of the calorimetric and kinematic data revealed a dissipation function proportional to the absolute value of the longitudinal plastic strain rate. (C) 2001 Elsevier Science B.V. All rights reserved.
\end{abstract}

Keywords: Lüders Band Propagation; Thermal And Dissipative Effects; Localization; Infrared thermography; Quasi-static Tensile Tests

\section{Introduction}

Strain localization phenomena, often qualified as 'plastic instabilities', are observed for a large variety of materials (metals, woods, polymers). Many experimental, theoretical and numerical studies have been conducted on this topic. Authors investigating elastoplastic or viscoplastic materials have naturally focused on kinematic aspects of localization, while taking into account various loading conditions [1-7]. Some studies have dealt with the microstructural origins of specific localization mechanisms like Lüders band propagation or Portevin-Le Chatelier effect [8-10]. Some others have assessed thermal effects associated with these different modes of strain localization [11-14]. Concerning Lüders band localization an interesting review can be found in [15].

The purpose of this paper is to show that recent advances in infrared image processing enable observation and quantitative analysis of the dissipative effects that accompany Lüders band propagation. Localization

\footnotetext{
* Corresponding author. Present address: LMéca, ESIA-Université de Savoie, 41 av, de la Plaine, 74000 Annecy, France.

E-mail address: herve.louche@esia.univ-savoie.fr (H. Louche).
}

due to necking, also observable with these imaging techniques, will be described elsewhere.

After reviewing the form of the heat equation used to interpret the thermal data, we then present the main characteristics of the experimental set-up, the numerical tools of the data processing developed to deduce heat source patterns from thermal images. We then focus on the most representative results from a large number of tests. Thermal and calorimetric effects accompanying the Lüders band are compared with kinematic measurements obtained by speckle image correlation [22]. The coupled analysis of kinematic fields and heat source distributions finally led us to test the thermodynamic validity of the predictions given by the academic perfectly plastic model.

\section{Heat emission during plastic deformation}

The thermomechanical framework used for interpretation is the so-called 'generalized standard materials' formalism [16]. In this framework, the heat conduction equation can be written as 
$\rho C\left(\frac{\partial T}{\partial t}+v \operatorname{grad}(T)\right)-\operatorname{div}(k \operatorname{grad}(T))=s_{\mathrm{e}}+s_{\mathrm{i}}$

where $T$ is the absolute temperature, $v$ the velocity vector, $\rho$ the mass density, $C$ the specific heat, $k$ the heat conduction tensor, $s_{\mathrm{e}}$ the volume heat source of external origin (e.g. radiation, Joule's effect), $s_{\mathrm{i}}$ the volume heat source of internal origin (e.g. thermoelastic effect, latent heat rate, intrinsic dissipation).

The experimental conditions of our quasi-static tests were based on the following hypotheses: the convective terms are negligible, $C$ is a material constant independent of the hardening state, $k$ is isotropic and also constant. The source $s_{\mathrm{e}}$ is exclusively due to heat exchange by radiation and is time independent. Finally, for the steel samples studied here, the thermoelastic effects were minor during plastic deformation in comparison to the dissipation and no stress-induced phase transformation occurred. Consequently, $s_{\mathrm{i}}$ can be identified with the intrinsic dissipation $d$.

When tests are performed on thin flat samples, it has been shown [17-19] that the temperature on the surface of the sample remains very close to the depth-wise averaged temperature. Taking into account all these hypotheses and integrating Eq. (1) over the thickness of the specimen, the heat equation can be simplified markedly into a two-dimensional partial differential equation:

$\rho C\left(\frac{\partial \theta}{\partial t}+\frac{\theta}{\tau_{\mathrm{th}}}\right)-k \Delta \theta=d$

where $\theta=\bar{T}-T_{0}$ is the difference between the temperature $\bar{T}$, averaged according to thickness, and the room temperature $T_{0}$, while $d$ is the mean dissipation per unit volume. The constant $\tau_{\text {th }}$ represents time characterizing heat losses perpendicular to the plane of the specimen. The heat conduction in the plane is taken into account by the two-dimensional Laplacian operator $\Delta \theta$.

\section{Experimental design and image processing}

The experimental set-up involved a $100 \mathrm{kN}$ tensioncompression testing machine coupled with an infrared camera (Agema $880 \mathrm{sw}$ ). The lens axis of the camera was kept fixed and perpendicular to the sample surface. Quasi-static monotonic tensile tests were performed on standard specimens $(2.5 \times 12.5 \times 50 \mathrm{~mm})$. The experiments were displacement controlled and the room temperature was kept constant $(300 \mathrm{~K})$. The European

Table 1

Chemical composition of S355MC steel

\begin{tabular}{llllllll}
\hline $\mathrm{C}$ & $\mathrm{Mn}$ & $\mathrm{P}$ & $\mathrm{S}$ & $\mathrm{Si}$ & $\mathrm{Al}$ & $\mathrm{Cu}$ & $\mathrm{N}$ \\
\hline 0.5 & 0.35 & $<0.02$ & $<0.01$ & $<0.04$ & 0.03 & $<0.1$ & $<0.009$ \\
\hline
\end{tabular}

grade of steel used is $\mathrm{S} 355 \mathrm{MC}$, which is frequently used in metal forming. Grain size is about $50 \mu \mathrm{m}$. The metallurgical and mechanical properties of this steel are described in [20], and its chemical composition is presented in Table 1.

Dissipation was determined by evaluating the left side of Eq. (2) and by using the digitized temperature images recorded by the infrared camera. The size of a thermal image was typically about $256 \times 30$ pixels. The pixel area was around $0.18 \times 0.22 \mathrm{~mm}^{2}$ under the optical conditions of our tests. As the thermal data was discrete and noisy, the differential operator was estimated by low-pass filtering and according to the properties of discrete Fourier transform and Fourier series. Since the number of images recorded per second was quite small (6 images $\left.\mathrm{s}^{-1}\right)$, the data filtering was mainly performed spatially. To avoid parasitic spatial frequencies due to the non-periodicity of the images and to reduce the boundary effect incidence - here substantially amplified by the Laplacian estimate - a parabolic periodic extension of the data was performed first. The thermal noise was simulated well by white noise characterized by a Gaussian probability distribution and a uniform power spectrum. This latter feature implies that no filtering method can completely eliminate the parasitic frequencies. Consequently, a calibration of the method in conditions close to the experimental situation is essential. The data processing was checked as follows: starting from a given heat source distribution, the corresponding temperature charts were calculated using spectral methods with realistic boundary conditions. The influence of the noise amplitude on the data processing was then tested. The heat sources reconstructed from the noisy thermal data were compared to the sources given above.

More information on the data processing and its performances can be found in $[18,19]$. As expected, the data processing check showed that the calculation error on the source determination increased sharply with the thermal noise amplitude. The unstable nature of the temperature-source passage (inverse problem) was due to the regularizing effects of the diffusion phenomena (direct problem). To limit noise effects, the cut-off frequencies of the numerical filters could be reduced, with a parallel decrease in source intensity and a spatial sprawl of zones where the heat sources were concentrated.

\section{Experimental results}

In the following, only results obtained on S355MC steel are mentioned. For the purposes of brevity and simplicity, we plotted temporal variations in temperature and dissipation profiles captured along the longitudinal axis of the sample. To further simplify the data 
interpretation, contour plots were chosen for quick visualization of the phenomenon patterns. Spatiotemporal representations were constructed with the abscissa axis representing the time (graduated per image number) and the ordinate axis being the longitudinal sample axis (graduated in pixels).

\subsection{Time course of thermal and dissipation profiles}

The different manifestations accompanying the plastic deformation of S355MC steel are presented in Fig. $1 \mathrm{a}$ and $\mathrm{b}$. They give an overview of the thermal and dissipative effects related to Lüders band propagation and necking development until the maximum load was reached.

\subsubsection{Thermal profiles}

The temperature profiles, observed during a monotonic tensile test performed at constant cross-head speed $\left(v=0.15 \mathrm{~mm} \mathrm{~s}^{-1}\right)$, are plotted in Fig. 1a. Two curves are superimposed on this diagram. The first one, representing the load versus time, correlates the thermal state of the sample with its loading state. The second curve shows the time-dependent changes in temperature at a specific point (pixel 100).

After a first period corresponding to thermoelastic behaviour, where temperature variations were quite homogeneous, i.e. negative and small $\left(\theta \approx-0.5^{\circ} \mathrm{C}\right)$, the development between images 36 and 50 of a temperature front $\left(\theta \leq 3^{\circ} \mathrm{C}\right)$ can be observed. The front initiated at one extremity of the gauge part (bottom) and then propagated at constant velocity. During strain hardening, the temperature variations increased regularly but in a heterogeneous way. The test was deliberately stopped near the maximum load (image 150). Then the specimen gradually recovered its thermal equilibrium.

Direct exploitation of thermal images is complex. Indeed, because of heat diffusion, it is difficult to determine whether temperature gradients are only due to natural heat conduction or partly result from localization phenomena. Analysis of the dissipation generating these thermal effects is therefore useful to visualize more precisely the localization zones.

\subsubsection{Dissipation profiles}

Two consecutive dissipation concentrations appear in Fig. 1b. As previously noted for temperature, time-dependent dissipation is plotted for pixel 100. During the plastic plateau, the first dissipation localization was characterized by a very intense and localized wave that propagated throughout the specimen at constant amplitude and velocity. These dissipative effects have been legitimately associated with Lüders band propagation. Next, a second kind of localization spread progressively over the specimen. This early and progressive localiza- tion of dissipation, observed even during strain hardening, was associated with the development of necking. Hereafter, we will only discuss the first mode of localization; those interested in the energy aspects of diffuse and localized necking should refer to $[18,19]$.

\subsection{Temperature front and dissipation wave}

In order to highlight the main characteristics of the spatial distribution of temperature and dissipation, we presented the results from a series of images taken during the plateau (Fig. 2).

A temperature front, inclined compared to the loading direction, appears in image No. 36 at the bottom of the sample. This front then propagates along the test section (Fig. 2a). The zone, where dissipation is localized, takes the form of a wave (Fig. 2b). This wave is inclined at $70 \pm 5^{\circ}$ relative to the loading direction and moves at constant velocity $\left(V_{\mathrm{LB}}=4 \pm 0.1 \mathrm{~mm} \mathrm{~s}^{-1}\right)$.

Temperature and dissipation profiles plotted at three times of band propagation enabled us to highlight the regularizing effects of heat diffusion (Fig. 3). Since the thermal diffusivity of the material is finite, the deformation process could be considered roughly as adiabatic at the very beginning of the test. Even though the temperature variations were very weak, image No. 36 shows a narrow zone where these variations are localized. The thermal images gradually become more complex to be interpreted as heat conduction. The heat capacity also plays an important role: the low temperature variations $\left(\approx 3^{\circ} \mathrm{C}\right)$ actually correspond to high energy rates $(d \approx$ $\left.6 \times 10^{6} \mathrm{~W} \mathrm{~m}^{-3}\right)$. The image processing finally revealed a relatively simple dissipation distribution, consistent with the phenomenon that we wanted to observe: a dissipation wave accompanied Lüders band propagation illustrating the irreversibility of such a mechanism.

\subsection{Lüders band velocity}

For S355MC steel, the dissipation effects were well marked and it was possible to derive Lüders band velocities from the heat source patterns for different values for the cross-head velocity $V_{\mathrm{CH}}$. An example of the results, obtained in a test carried out at $V_{\mathrm{CH}}=0.04$ $\mathrm{mm} \mathrm{s}^{-1}$ is presented in Fig. 4 (test ab1).

In this figure we can observe the propagation of a Lüders band originating at image 108, in the grip zone of the top head of the sample. The band velocity is $V_{\mathrm{LB}}=1 \mathrm{~mm} \mathrm{~s}^{-1}$.

Seven temperature and dissipation images are plotted in Fig. 5. Two waves appear simultaneously at the extremities of the sample (image 108), but only the band located at the highest part succeeded in propagating. Due to thermal inertia, the temperatures at the bottom part of the sample kept a trace of the dissipation band. 

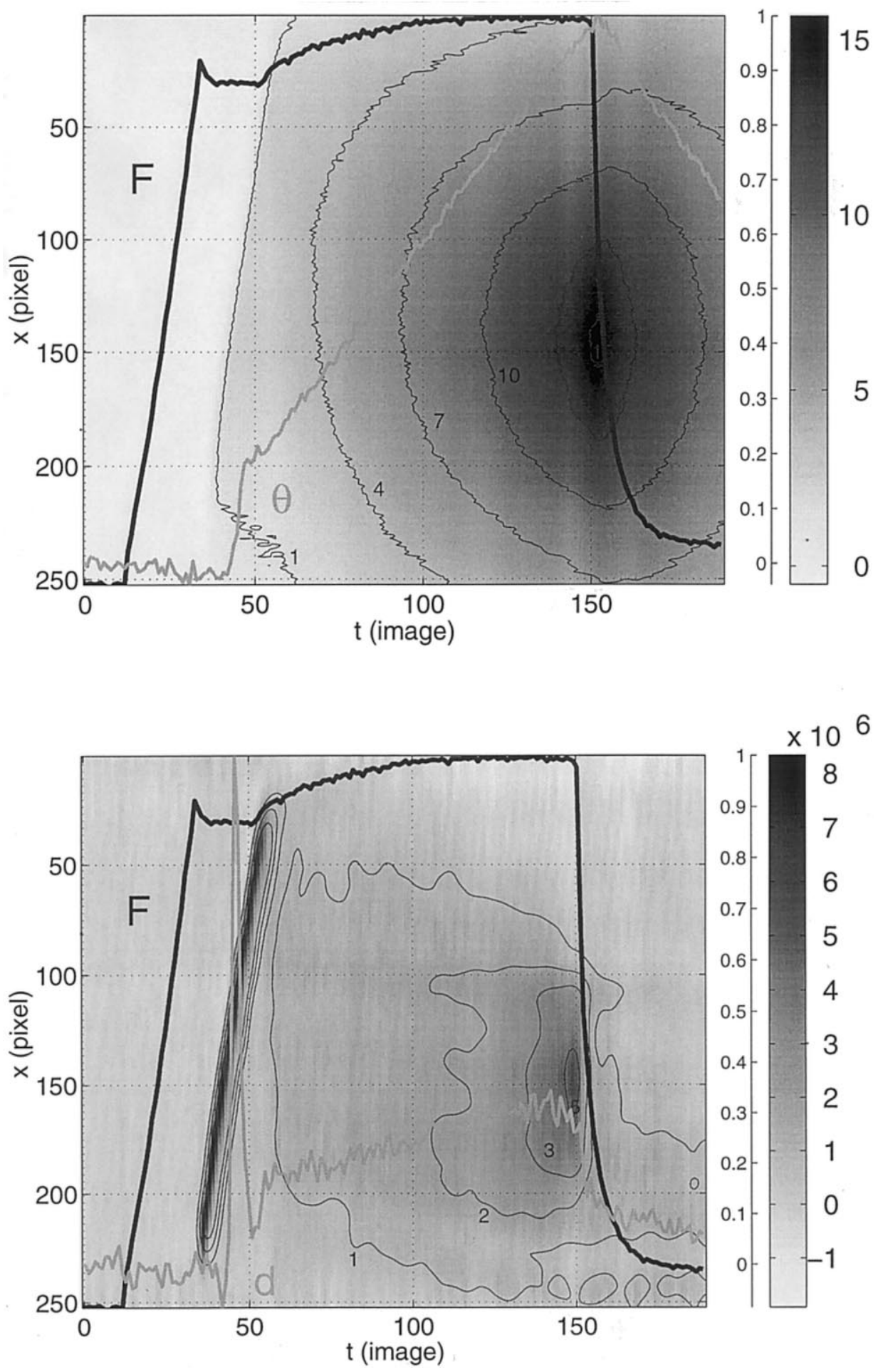

Fig. 1. (a) (Test aa6 - cross-head velocity). Background image: spatiotemporal variations in a lengthwise temperature profile (sampling frequency: 2 images $\mathrm{s}^{-1}$ ). Temperature levels are given by the colorbar graduated in ${ }^{\circ} \mathrm{C}$. Superimposed curves represent the load evolution $F$ and the temperature variation $\theta$ (at pixel 100 ), normalized by their maximal values $\left(F_{\max }=16.2 \mathrm{kN} ; \theta_{\max }=13.6^{\circ} \mathrm{C}\right)$. (b) (Test aa6 cross-head velocity $V_{\mathrm{CH}}=0.15 \mathrm{~mm} \mathrm{~s}^{-1}$ ). Image processing results. Background image: spatiotemporal variations in a lengthwise heat source profile (in $\mathrm{W} \mathrm{m}^{-3}$ ). Superimposed curves represent the load evolution $F$ and the heat sources $\bar{S}$ (at pixel 100), normalized by their maximal values $\left(F_{\max }=16.2 \mathrm{kN}\right.$, $\left.d_{\max }=8 \times 10^{6} \mathrm{~W} \mathrm{~m}^{-3}\right)$.

To study the band velocity, a series of tests were conducted at three different cross-head speeds $\left(V_{\mathrm{CH}}=\right.$ $0.04,0.15$, and $\left.0.4 \mathrm{~mm} \mathrm{~s}^{-1}\right)$. At each time, a single band propagating at constant velocity was observed. The different velocity measurements are reported in Fig. 6 . The linear variation in the propagation velocity 
$V_{\mathrm{LB}}$ are in quite close agreement with previously published results. For $n$ bands, under certain conditions, Hahn [21] showed that:

$V_{\mathrm{LB}}=\frac{V_{\mathrm{CH}}}{n \varepsilon_{\mathrm{LB}}}$ where $\varepsilon_{\mathrm{LB}}$ is the strain (often called 'Lüders strain') locally generated by the passage of a Lüders band. A regression line throughout the experimental points is plotted in Fig. 6. It leads to $\varepsilon_{\mathrm{LB}}=4.2 \%$. In parallel, this strain has been evaluated using an extensometer. This second estimate is about $3.3 \%$.

Test aa6 - Thermal front propagation

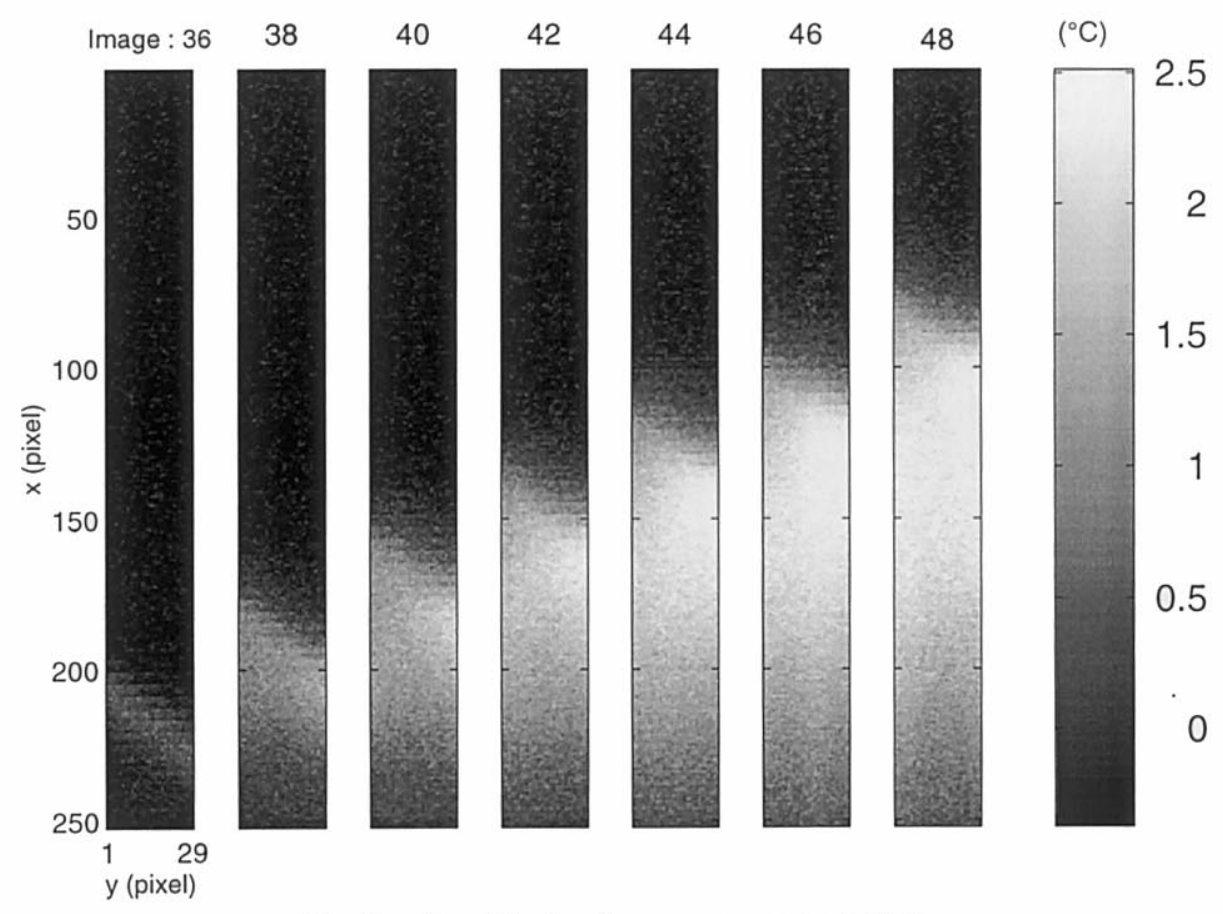

Test aa6 - Dissipation wave propagation

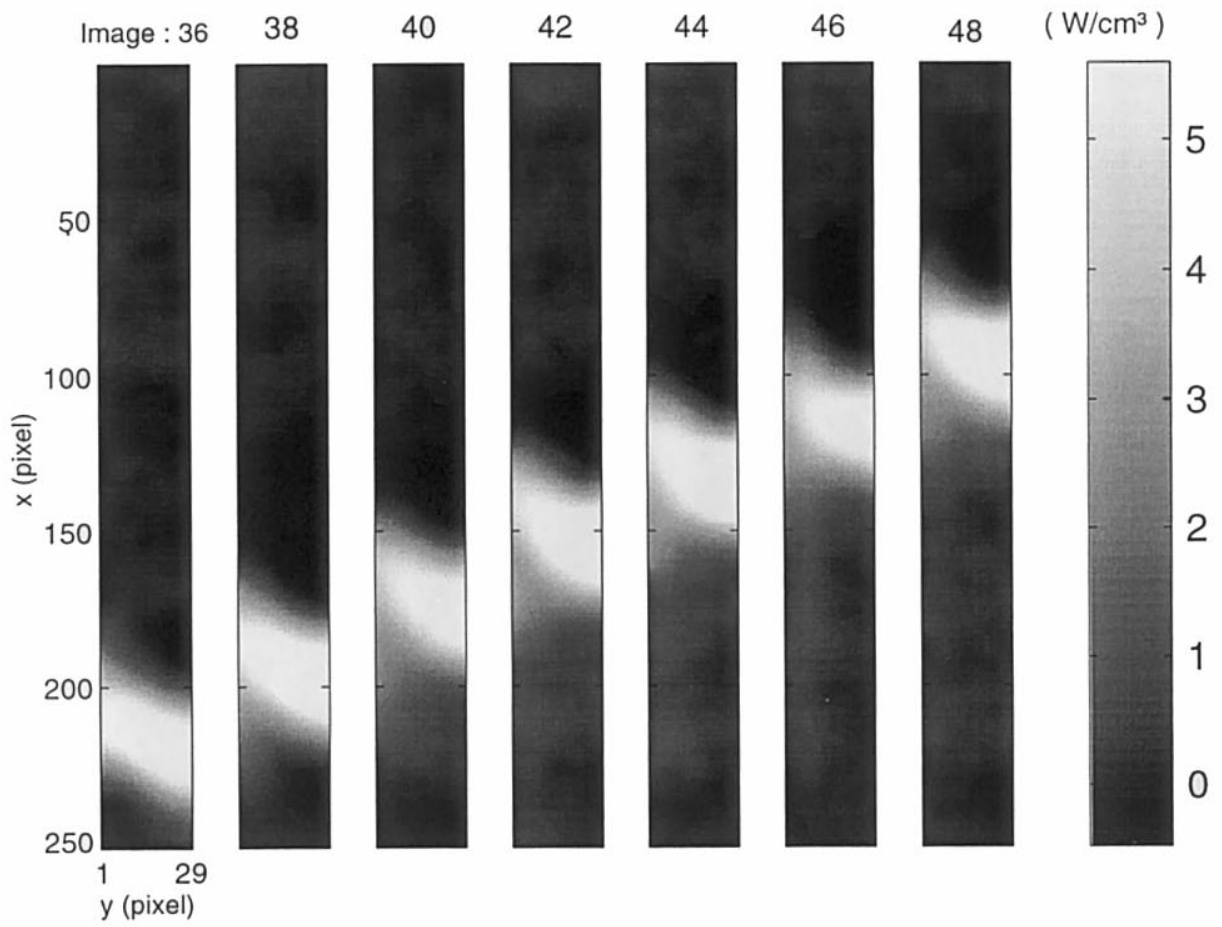

Fig. 2. (Test aa6 $-V_{\mathrm{CH}}=0.15 \mathrm{~mm} \mathrm{~s}^{-1}$ ). Propagation along the gauge part of: (a) a thermal front; (b) a dissipation wave. 


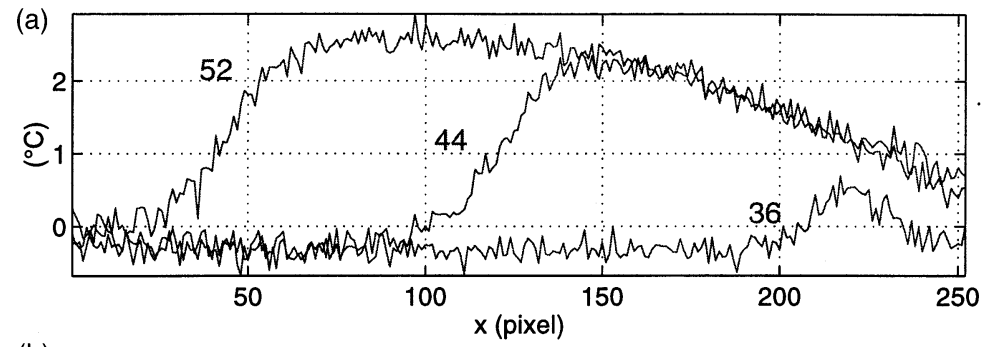

(b)

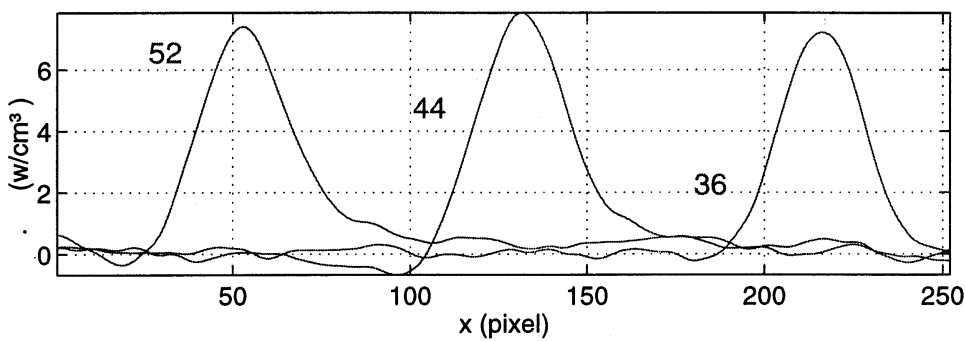

Fig. 3. (Test aa6 $-V_{\mathrm{CH}}=0.15 \mathrm{~mm} \mathrm{~s}^{-1}$ ). Lengthwise profiles at different moments of the plastic plateau (images 36 , 44 and 52): (a) thermal profiles associated with Lüders band propagation, (b) dissipation profiles. This latter result, taking into account the diffusion phenomena, shows the regular progression of a wave whose form remains roughly constant.

\section{Test ab1}

a) TB

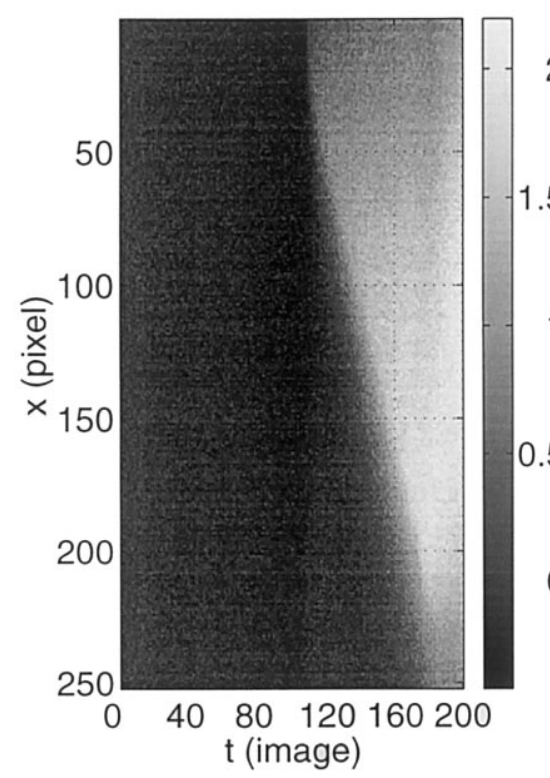

b) d

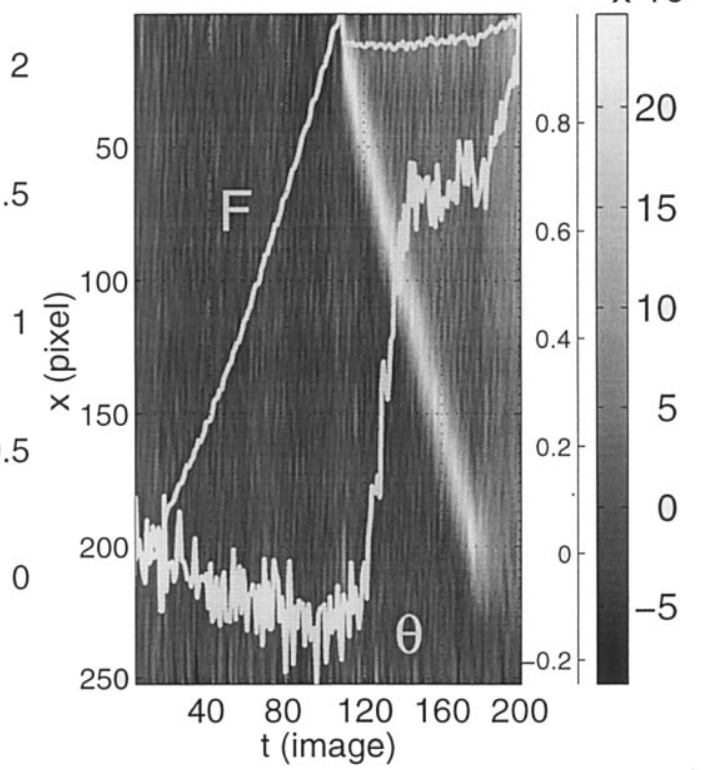

Fig. 4. (Test ab1 $-V_{\mathrm{CH}}=0.04 \mathrm{~mm} \mathrm{~s}^{-1}$ ). Spatiotemporal variations in a lengthwise profile of: (a) temperature variation $\left({ }^{\circ} \mathrm{C}\right)$, (b) heat sources $\left(\mathrm{W} \mathrm{cm}^{-3}\right), F_{\max }=15.8 \mathrm{kN}$.

\subsection{Comparison with kinematic measurements}

Displacement measurements obtained by digital image correlation were obtained on the same steel and under the same experimental conditions [22]. For S355MC steel, during Lüders band propagation, it has been shown that strain rate distributions calculated from displacement measurements take the same form as the dissipation wave previously presented (Fig. 7). Note that the peaks of these waves remain almost perfectly proportional. In a first good approximation, the proportionality coefficient is equal to the yield stress $\sigma_{0}$ classically obtained by dividing the load during the plateau by the cross-section of the sample. The dissipation observed during Lüders band propagation is then compatible with the one-dimensional perfectly plastic model: 
$d=\sigma_{0}|\dot{\varepsilon}|$

\section{Comparison with some published results}

We already mentioned for S355MC steel that the dissipation wave angle relative to the axial direction is about $70^{\circ}$. The estimate of this angle may become quite complex since the wave front is rather fuzzy (e.g. see Fig. 2b). This elevated value contrasts with measurements made by others $([15,23])$ where the angle varies from 45 to $55^{\circ}$. However, elevated values of the angle of inclined bands have already been noted previously [24] in particular for coarser grained specimens. Finally, the value of $70^{\circ}$ was confirmed on the same steel by

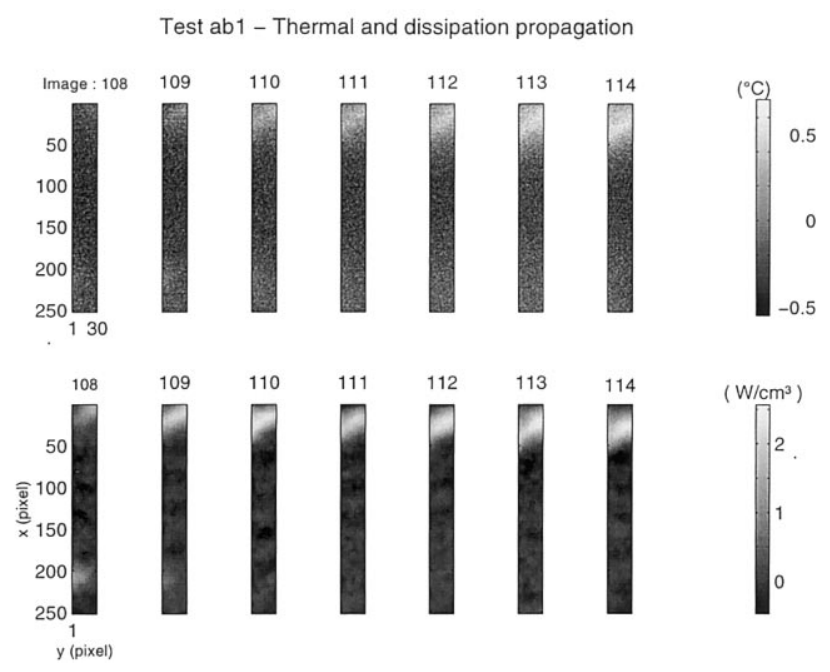

Fig. 5. (Test ab1 $-V_{\mathrm{CH}}=0.04 \mathrm{~mm} \mathrm{~s}^{-1}$ ). Top: seven thermal images for illustrating temperature front propagation. Bottom: corresponding heat source distributions showing the propagation of dissipation waves.

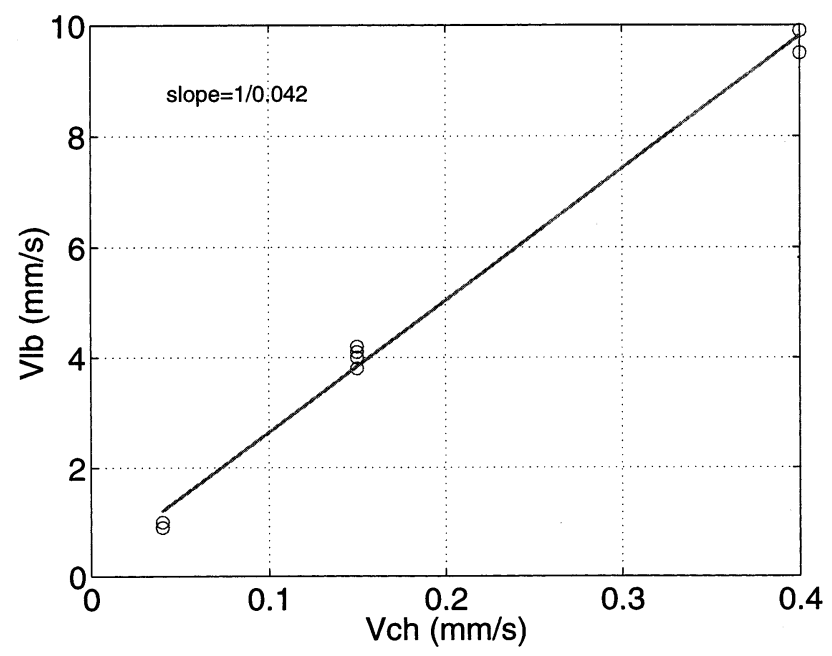

Fig. 6. Lüders band propagation velocity $V_{\mathrm{LB}}$ as a function of the cross-head velocity $V_{\mathrm{CH}}$.
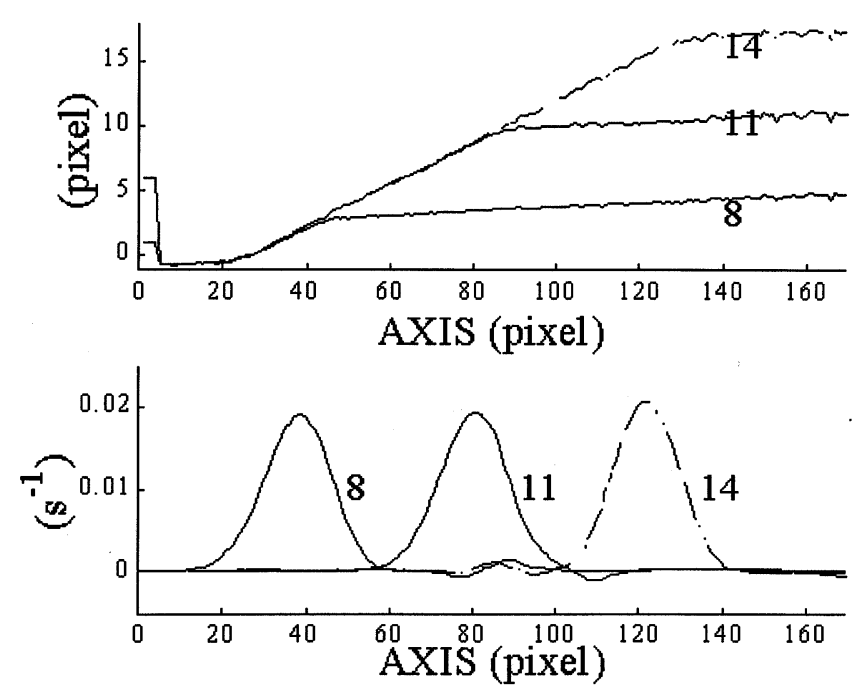

Fig. 7. $V_{\mathrm{CH}}=0.15 \mathrm{~mm} \mathrm{~s}^{-1}$. Longitudinal profiles of: (top) the longitudinal displacement component; (bottom) the Lagrangian tensile strain rate obtained at three different times during the plastic plateau (images 8, 11, 14, from [23]).

kinematic measurements [22] and optical observation of the surface roughness.

The thermal and calorimetric results plotted in Fig. 2 may be also compared to other previous experimental findings. For instance, we name hereafter those presented in [25] on Lüders band propagation in niobium and those recently obtained by [26,27], which deal with the propagation of phase transformation fronts in a shape memory alloy (NiTi). In [25], the band displacement is revealed by a thin layer of a brittle lacquer applied to the specimen surface, this layer being broken by the passage of the band. In [26,27] the macroscopic deformation induced by the band passage destroys an oxide layer, pregenerated by metallurgical treatment, and leads to reflectivity changes. This leads to colour contrasts enabling the authors to identify the transformed and non-transformed portions of the specimens. Note that temperature changes at surface samples, also recorded by infrared thermal imaging [26], show thermal fronts like the ones described in this paper. In addition, these authors propose an analogy between the transformation front propagation and Lüders band propagation in mild steels.

The asymmetric shape of the dissipation wave plotted in Fig. 3 was essentially due to the presence of a trail at the back of the wave. Such profiles are in agreement with the strain rate patterns proposed by [28] and [29] to model the sudden propagation of dislocations generating Lüders bands.

A theoretical result, strengthening the coupling effects between thermal and mechanical variables, concerns the propagation of thermomechanical fronts obtained at very low temperature (a few K). These fronts are generated by periodic instabilities (like PLC 
effect) observed in single or polycrystals [10]. At these temperatures, glide velocity of dislocations, i.e. the plastic strain rate, is strongly temperature dependent. Its variations are then theoretically coupled with temperature changes through a dissipation term induced by the dislocation glide itself. The dissipation appears as source in the heat equation so that the diffusion phenomena influence the balance of dislocation densities. The authors of [10] then obtained a system of coupled thermomechanical equations. The solution of this system allows the prediction of temperature fronts, strain rate and mobile dislocation densities.

\section{Concluding comments}

Displacement-controlled tensile tests for S355MC steel showed singular thermal effects during the plastic plateau. The low amplitude $\left(2\right.$ or $\left.3^{\circ} \mathrm{C}\right)$ thermal front moved at constant velocity along the test section of the specimen and was associated with Lüders band propagation. Infrared image processing allowed an analysis of heat sources (dissipation) generating these thermal effects. We show that the dissipation distribution takes the form of one wave moving at constant velocity. Some characteristics of this wave, like its orientation and velocity, are measured and the results are in agreement with previous results. To check and strengthen the validity of this experimental investigation, energy results were compared to kinematic measurements obtained by digital image correlation. The dissipation and strain rate wave forms, obtained on the same material and in the same experimental conditions, were very similar. This result is not surprising from a thermodynamic point of view, i.e. loci where the strain rate was the highest were those where irreversibility preferentially developed, and consequently, where the dissipation intensity was highest. We found that the dissipation vs. the longitudinal strain rate ratio was very close to the yield stress. This result is consistent with the prediction of the academic one-dimensional perfectly plastic model. Nevertheless, such a model is unable to predict the localization mechanism. The use of a more realistic model that takes microstructural information into account (as in [28] for instance) will be considered in the near future.

\section{References}

[1] A. Considère, Annales des Ponts et Chaussées 9 (1885) 574.

[2] R. Hill, J. Mech. Phys. Solids 6 (1958) 236.

[3] J. Mandel, Rhéologie et Mécanique des sols, in Kravtchenko et Syries, IUTAM Symposium, Grenoble, 1964, p. 58.

[4] E.W. Hart, Acta metall. 15 (1967) 351.

[5] J.R. Rice, J. Theor. Appl. Mech. (1976) 207.

[6] C. Fressengeas, A. Molinari, Acta Metall. 33 (1985) 387.

[7] A. Benallal, Arch. Mech. 44 (1) (1992) 15.

[8] Y. Estrin, L.P. Kubin, Mater. Sci. Eng. A137 (1991) 125.

[9] H. Neuhäuser, Int. J. Plast. 9 (1993) 421.

[10] M. Zaiser, P. Hähner, Phys. Stat. Sol. (b), Rev. 199 (1997) 267.

[11] G. Ferron, Mater. Sci. Eng. 49 (1981) 241.

[12] Y.H. Kim, R.H. Wagoner, Int. J. Mech. Sci. 29 (3) (1987) 179.

[13] A. Marchand, J. Duffy, J. Mech. Phys. Solids 36 (3) (1988) 251.

[14] B. Lisiecki, L. Kubin, Y. Estrin, Metal Sci. Tech. 10 (1) (1992) 10.

[15] E.O. Hall, Yield Point Phenomena in Metals and Alloys, Plenum, New York, 1970.

[16] B. Halphen, Q.S. Nguyen, J. Méch. 14 (1) (1975) 39.

[17] A. Chrysochoos, Actes du Colloque National Photomécanique 95, Eyrolles, Cachan, France, 1995, p. 203.

[18] H. Louche, Ph.D. Thesis, Université Montpellier II, France, 1999.

[19] A. Chrysochoos, H. Louche, Int. J. Eng. Sci. 38 (16) (2000) 1759.

[20] G. Béranger, G. Henry, G. Sanz, Le livre de l'acier, Lavoisier Tech et Doc, 1994.

[21] G.T. Hahn, Acta Metall. 10 (1962) 727.

[22] B. Wattrisse, M. Némoz-Gaillard, J.M. Muracciole, A. Chrysochoos, in: Y. Berthaud (Ed.), Photomécanique 98, Marne La Vallée, France, 1998, p. 21.

[23] B. Jaoul, J. Mech. Solids 9 (2) (1961) 69.

[24] V.S. Ananthan, E.O. Hall, Acta Metall. Mater. 12 (1991) 3153.

[25] H. Conrad, G. Stone, J. Mech. Phys. Solids 12 (1964) 139.

[26] J.A. Shaw, S. Kyriakides, Acta Mater. 45 (2) (1997) 683.

[27] J.A. Shaw, S. Kyriakides, Int. J. Plast 13 (10) (1998) 837.

[28] Y. Estrin, L.P. Kubin, Rev. Phys. Appl. 23 (1988) 573.

[29] P. Hähner, Appl. Phys. A58 (1994) 41. 